\title{
Treatment of Biogenic Iron-Containing Materials
}

\author{
Maya G. Shopska, ${ }^{a, *}$ Zara P. Cherkezova-Zheleva, ${ }^{a}$ Daniela G. Paneva, ${ }^{a}$ Vilma Petkova, ${ }^{b}$ \\ Georgi B. Kadinov, ${ }^{a}$ and Ivan G. Mitov ${ }^{a}$ \\ ${ }^{a}$ Institute of Catalysis, Bulgarian Academy of Sciences, 1113 Sofia, Bulgaria \\ ${ }^{\mathrm{b}}$ Acad. Ivan Kostov Institute of Mineralogy and Crystallography, Bulgarian Academy of Sciences, 1113 Sofia, Bulgaria
}

RECEIVED OCTOBER 7, 2013; REVISED FEBRUARY 14, 2014; ACCEPTED FEBRUARY 27, 2014

\begin{abstract}
Biogenic iron oxides could find application in catalysis but their structure and composition should be well characterized. The content of organic rests due to their origin should also be controlled. Samples of natural biomass and biomass obtained after cultivation in Adler's medium of the SphaerotilusLeptothrix group of bacteria were treated by different techniques to reduce or totally remove the organic residues. The aim of the study was to find procedures, which prevent changes in the oxidation state of the iron and of the type of iron-containing compound(s) during treatment. Mössbauer spectroscopy, IRS, DTA, and SEM were used in the study. Chemical treatment with $\mathrm{H}_{2} \mathrm{O}_{2}$ or $\mathrm{NaOH}$ at room temperature did not significantly change the samples. Thermal treatment in oxidative flow mixture conducted up to $250{ }^{\circ} \mathrm{C}$ resulted in a transformation of the iron-containing phases only. The organic matter, which is included in the structure of the particles, cannot easily be affected. DTA revealed that removal of organic rests occurred in the interval of $250-600{ }^{\circ} \mathrm{C}$. However, the transformation of the initial compounds could not be prevented using such a treatment.
\end{abstract}

Keywords: inorganic compounds, Sphaerotilus-Leptothrix group of bacteria, Mössbauer spectroscopy, thermogravimetric analysis, Fourier transform infrared spectroscopy

\section{INTRODUCTION}

At the present time iron-containing materials obtained by bacteria, fungi, yeasts and viruses give rise to certain interest since no (or at least minimum) energy consumption is necessary for their synthesis. ${ }^{1-4}$ Bacteria from the Sphaerotilus-Leptothrix group participate in biogeochemical rotation of the iron that occurs in the lithosphere. It is a fundamental geological process of iron oxidation performed by microorganisms ${ }^{5}$ where, firstly iron is mobilized, then it is used and assimilated by the microbes and finally it is immobilized and deposited. The deposition of ferric ions is extracellulary in the form of sheaths and it is not related to energy supply. ${ }^{6-8}$ Interest to the biosynthesis of iron-containing compounds is dictated from the fact that there are methods to produce nanosized iron oxide compounds (hematite, magnetite, goethite, etc.) but they are relatively expensive or use harmful chemical materials, the yields being not high enough. ${ }^{9,10}$ Biogenic iron materials have application to electrical devices and electrochemical sources, ${ }^{3,11,12}$ purification of waters, soil and air, ${ }^{13-17}$ and catalysis. Biogenic iron oxides have been applied as catalysts in reactions of oxidation ${ }^{10,18-20}$ or as an (immobilising) support for catalysts of very high activity. ${ }^{2,21-23}$ Investigations in this field are still scarce and concentrated only on a small number of reactions.

The use of biogenic materials in heterogeneous catalytic reactions is based on specificity of their composition and structure, which determine valuable properties of the surface: high specific surface area, active sites of unusual coordination, adsorption sites of appropriate acidic or basic character. Usually, the samples of biogenic iron are impure - they contain organic rests. Despite formed sheaths, hollow microtubes and twisted stalks are extracellulary precipitated $^{6-8}$ they contain organic carbon. All these forms of bacterially formed mineral sheaths have wall structure consisting of iron (oxy)hydroxides nanospheres and organic carbon inclusion, as shown in Refs. 24-27. Some authors even consider that inorganic compound(s) and organics are one united entity, i.e. biogenic iron is a hybrid material in its nature. ${ }^{28,29}$ Organic residues can play the role of basic centres on the surface of the biogenic material. ${ }^{10}$ The organic species cannot be totally removed even after repeated water washing and their amount cannot be controlled. From one side, the

\footnotetext{
* Author to whom correspondence should be addressed. (E-mail: shopska@ic.bas.bg)
} 
reason for this is the applied mode of dry sample preparation. In general, it includes operations of decantation, filtration, repeated washing with distilled water, and drying. ${ }^{10,20}$ The result is that the bacteria remain partly in the sample. On the other hand, the results depend on the process of sheath formation and/or the factors that influence this process but the acquired data are controversial ${ }^{30-34}$ and not well explained particularly if bacteria are cultivated under laboratory conditions. These peculiarities create uncertain composition of the materials based on biogenic iron (oxy)hydroxides. Despite some successful attempts to use biogenic materials for catalyst preparation without organics removal, ${ }^{10,21-23}$ in any case the synthesis of a catalyst requires known and constant composition of the used material(s) that will define its properties.

In own study, a natural biogenic material, collected from water brooks at Vitosha mountain (Bulgaria) and identified as a product of normal cell metabolites of the Sphaerotilus-Leptothrix group of bacteria, has recently been characterized. ${ }^{20}$ It was proved that this matter consisted of iron (oxy)hydroxide and exhibited low catalytic activity in the reaction of $\mathrm{CO}$ oxidation. Nevertheless, this biogenic material has the potential to be used as catalyst (after suitable modification) or catalyst ingredient. As it was mentioned above, it is a problem that this material contains organic impurities (bacterial rests).

The aim of the present study was to investigate appropriate chemical/thermal treatment(s) of biogenic material of the Sphaerotilus-Leptothrix group of bacteria in order to reduce considerably or remove organic contamination. Since following certain pretreatments, changes in the oxidation state of the iron and of the type of the iron-containing compound(s) might occur, this study may be helpful in answering the question how to prevent undesired transformations, so as how these transformations have influence on the structure of nanosized biogenic material(s).

\section{EXPERIMENTAL}

\section{Materials}

The biomass used in this study was collected from water brooks at Vitosha mountain, in a region above 1000 metre altitude. Samples were kept at $4{ }^{\circ} \mathrm{C}$ in the laboratory and then placed in closed containers in order to create a natural habitat for a proper and selective cultivation. Throughout the text, the latter material will be denoted as 'Natural biomass'.

Different nutrient media have been used for selective cultivation of iron bacteria. ${ }^{35-39}$ The medium of Adler $^{35}$ is one of those recommended for cultivation and isolation of the iron bacteria. Previous investigations have shown that Adler's medium is suitable for our aims giving intensive multiplication of bacteria, enough population for pure cultures isolation, and accumulation of relatively large amounts of iron-containing biogenic material. ${ }^{40}$ The composition of the used medium is complex: sodium lactate, yeast extract, ascorbic acid, $\mathrm{MgSO}_{4} \cdot 7 \mathrm{H}_{2} \mathrm{O}, \mathrm{K}_{2} \mathrm{HPO}_{4},\left(\mathrm{NH}_{4}\right)_{2}\left[\mathrm{Fe}\left(\mathrm{SO}_{4}\right)_{2}\right] \cdot 6 \mathrm{H}_{2} \mathrm{O}$, distilled $\mathrm{H}_{2} \mathrm{O}$. These ingredients provide the bacteria with carbon, main biogenic elements, iron, different growth factors, and microelements required for their growth and metabolism. The cultivation process was carried out in special flasks under static conditions at $16{ }^{\circ} \mathrm{C}$. After one-month period of cultivation, the biomass was collected through decantation, washed with distilled water, and dried at $40{ }^{\circ} \mathrm{C}$ for $24 \mathrm{~h}$. The biomass thus obtained was denoted as 'Adler-K'.

\section{Methods}

Mössbauer (spectral) analysis was carried out by using a Wissenschaftliche Elektronik $\mathrm{GmbH}$ instrument operating at a constant acceleration mode, using a ${ }^{57} \mathrm{Co} / \mathrm{Cr}$ source and $\alpha$-Fe standard. The following parameters of hyperfine interactions of the Mössbauer spectral components were determined by computer fitting: isomer shift (IS), quadrupole splitting (QS), hyperfine effective field (Heff) as well as line width (FWHM) and component relative weight $(\mathrm{G})$. Infrared spectra of the samples were recorded on a Nicolet 6700 FTIR spectrometer (Thermo Electron Corporation) using the method of dilution of studied material in $\mathrm{KBr}$ pellets $(0.5 \%)$. The spectra were collected both in the middle (400-4000 $\left.\mathrm{cm}^{-1}\right)$ and far $\left(250-650 \mathrm{~cm}^{-1}\right)$ IR regions using 50 scans.

TG(dTG)-dTA curves were recorded by a Stanton Redcrof thermal installation in air flow $\left(60 \mathrm{~mL} \mathrm{~h}^{-1}\right)$ at a $10 \mathrm{deg} \mathrm{min}^{-1}$ heating rate from 20 to $860 / 1000{ }^{\circ} \mathrm{C}$. Analysis was carried out using $10 \mathrm{mg}$ of studied sample.

Microscope images were recorded on a JEOL JSM 5300 scanning electron microscope working at accelerating voltage up to $20 \mathrm{keV}$ and magnification up to 50000x.

Particle-size distribution in the thermally treated samples was investigated by photon cross-correlation spectroscopy (PCCS). Measurements were performed using a Nanophox instrument (Sympatec GmbH). Prior to measurement the investigated samples were dispersed in distilled water, subjected to supersonic treatment, and placed in the temperature-controlled sample holder $\left(25{ }^{\circ} \mathrm{C}\right)$ at least three minutes before start. Five measurements with each sample were carried out over a period of $600 \mathrm{~s}$. Laser intensity and cuvette position were adjusted to obtain an average count-rate at the detector of about $300 \mathrm{kcps}$. 


\section{RESULTS AND DISCUSSION}

\section{Description of the Studied Samples}

IR spectra of the studied materials in both regions (250600 and $400-4000 \mathrm{~cm}^{-1}$ ) are presented in Figure 1. The spectrum of the Natural biomass sample in the far-IR region is characterized by poorly resolved bands at about 370 and $415 \mathrm{~cm}^{-1}$ and a shoulder at about $460 \mathrm{~cm}^{-1}$ (Figure 1b, spectrum 1). Bands at 415, $460 \mathrm{~cm}^{-1}$ (with a shoulder at $670 \mathrm{~cm}^{-1}$ ), 800, 890, 1386, 1644 , and $3150 \mathrm{~cm}^{-1}$ are registered in the mid-IR region. All noted bands show presence of $\alpha-\mathrm{FeOOH}$ in accordance with literature data. ${ }^{41-44}$ These absorption bands arise from $\mathrm{Fe}-\mathrm{OH}, \mathrm{Fe}-\mathrm{O}$ and $\mathrm{O}-\mathrm{H}$ vibrations. The bands at $370,415,460 \mathrm{~cm}^{-1}$ are related to $\mathrm{Fe}-\mathrm{O}$ lattice vibrations. The bands at 800 and $890 \mathrm{~cm}^{-1}$ are assigned to $\mathrm{OH}$-bending vibrations and the band at $3150 \mathrm{~cm}^{-1}$ is characteristic of the stretching vibration of hydroxyl groups in the structure of $\alpha-\mathrm{FeOOH}$.

The bands at 360 and $470 \mathrm{~cm}^{-1}$ (with a shoulder at $550 \mathrm{~cm}^{-1}$ ) and the narrow band of medium intensity registered in the range $1000-1100 \mathrm{~cm}^{-1}$ in the spectra of the Adler-K sample are characteristic of $\gamma$-FeOOH. ${ }^{41,43,45}$

Also, the studied materials demonstrate bands at $3450,3000-2800,1620$, and $1380 \mathrm{~cm}^{-1}$ in the region of $600-4000 \mathrm{~cm}^{-1}$. The bands at 3450 and $1620 \mathrm{~cm}^{-1}$ result from bending vibrations of hydrogen-bonded hydroxyl groups and physically adsorbed water on the surface of the samples, respectively. ${ }^{46}$

The presence of residues originating from live matter is observed in the collected infrared spectra of both the samples. The bands registered in the region 2800-3000 and at $1382 \mathrm{~cm}^{-1}$ are characteristic of hydrocarbon groups from organic rests. ${ }^{46}$ Very week bands at $1230,1153,1119,1070$, and $1030 \mathrm{~cm}^{-1}$ are assigned to the characteristic vibrations of $\mathrm{C}-\mathrm{O}, \mathrm{C}-\mathrm{O}-\mathrm{C}$ and $\mathrm{C}-\mathrm{O}-\mathrm{P}$ groups in oligo- and polysaccharides. ${ }^{47}$ The procedure of sample preparation is compatible with the presence of compounds/rests originating from live matter: fatty acid components of the cell membrane and oligo- and polysaccharides building a bacterial capsule.

Detailed description of the spectra and their interpretation have been presented in our previous work (Ref. 20). Infrared spectra, collected by using $\mathrm{KBr}$ pellets, can hardly be used for quantitative analysis. Nevertheless, comparison of the spectra in the range 2750-3000 $\mathrm{cm}^{-1}$ supposes a larger hydrocarbon amount in the sample cultivated in Adler's medium (Adler-K) than that of the Natural biomass.

Mössbauer spectra of the studied samples can be described by two types of components. Quadrupole doublets (Dbl) are components without hyperfine magnetic structure. Sextets $(\mathrm{Sxt})$ are components that
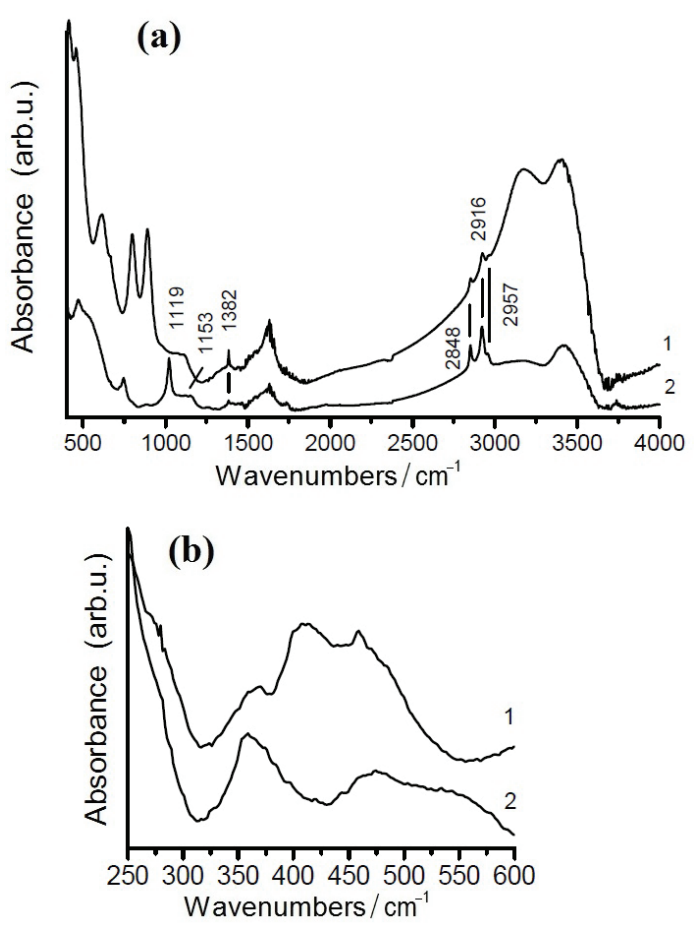

Figure 1. Mid- (a) and Far-IR spectra (b) of the studied samples. 1 - Natural biomass, 2- Adler-K - Ref. 20.

show availability of hyperfine magnetic structure. The Mössbauer parameters obtained after mathematical treatment of the experimentally registered spectra are listed in Table 1. The results show that iron ions in the $3+$ oxidation state occur in the Natural biomass sample. The parameters are characteristic of $\alpha-\mathrm{FeOOH}$ particles of different size: ultra- and highly dispersed. $\alpha-\mathrm{FeOOH}$ particles with superparamagnetic behaviour have a 10-13 nm size. Larger particles (calculated according to the CME model) are about $30 \mathrm{~nm}$ in size. Calculated hyperfine parameters show presence of iron ions of different oxidation state in the Adler-K sample. They are included in different phases: $\gamma$-FeOOH and non-stoichiometric $\mathrm{Fe}_{3-x} \mathrm{O}_{4}$. The calculated value of $x$ (number of vacancies) for the magnetite phase in the sample is 0.082 . The Mössbauer spectrum of this sample contains a doublet component due to high-spin octahedrally coordinated $\mathrm{Fe}^{3+}$ ions that belong to non-resolved iron oxide and/or an iron hydroxide phase with particles, lower than $10 \mathrm{~nm}$ in size, that have superparamagnetic behaviour. Detailed information about Mössbauer data, computational models, and the results discussed above can be found in our previous paper (Ref. 20).

Slight differences between the compositions of the Natural biomass and Adler-K sample can be attributed to biotic and abiotic $\mathrm{Fe}^{2+}$ oxidation that occur in synthetic medium under the selected conditions. Reactions that may be realized are chemical, passive, and bacterial oxidation. Competitive redox processes, 
Table 1. Calculated values of Mössbauer parameters of the Natural biomass sample and Adler-K sample obtained by cultivation Ref. 20

\begin{tabular}{|c|c|c|c|c|c|}
\hline Sample / Component & IS $/ \mathrm{mm} \cdot \mathrm{s}^{-1}$ & $\mathrm{QS} / \mathrm{mm} \cdot \mathrm{s}^{-1}$ & $H_{\mathrm{eff}} / \mathrm{T}$ & $\mathrm{FWHM} / \mathrm{mm} \cdot \mathrm{s}^{-1}$ & $G / \%$ \\
\hline \multicolumn{6}{|l|}{ Natural biomass } \\
\hline Sxt $-\alpha-\mathrm{FeOOH}$ & 0.32 & -0.07 & 27.0 & 1.66 & 50 \\
\hline Dbl - $\alpha$-FeOOH-SPM & 0.36 & 0.55 & & 0.46 & 50 \\
\hline \multicolumn{6}{|l|}{ Adler-K } \\
\hline $\mathrm{Sxt} 1-\mathrm{Fe}_{3} \mathrm{O}_{4}$ & 0.30 & 0.00 & 48.8 & 0.53 & 15 \\
\hline $\mathrm{Sxt} 2-\mathrm{Fe}_{3} \mathrm{O}_{4}$ & 0.66 & 0.00 & 45.7 & 1.08 & 16 \\
\hline $\mathrm{Dbl}-\mathrm{Fe}^{3+}-\gamma-\mathrm{FeOOH}$ & 0.37 & 0.55 & - & 0.37 & 38 \\
\hline $\mathrm{Dbl}-\mathrm{Fe}^{3+}-\mathrm{SPM}$ & 0.37 & 0.75 & - & 0.46 & 31 \\
\hline
\end{tabular}

change of $\mathrm{pH}$, usage of asynchronous bacterial culture, and concentration of ferrous ions direct chemical equilibrium to formation of iron compounds that are different in comparison with those obtained in nature.

\section{Chemical Treatment at Room Temperature}

Attempts to remove organic rests from the studied samples were made by using $30 \% \mathrm{H}_{2} \mathrm{O}_{2}$ or $31 \% \mathrm{NaOH}$ aqueous solutions. The selected reagents have the potential to affect the organic ingredient and at the same time a contact with them does not change the oxidation state of the iron in the basic compound(s). In addition, these reagents do not import secondary hardly removable ions in the treated material. The samples and the respective reagent were put in contact at room temperature for one week under periodic shaking. After that, the suspension was dried at $40{ }^{\circ} \mathrm{C}$ (in the case of $\mathrm{H}_{2} \mathrm{O}_{2}$ treatment) or the liquid was decanted, then the sample was washed several times with distilled water and dried at the same temperature ( $\mathrm{NaOH}$ treatment).

The infrared measurements of chemically treated products showed that the biogenic samples were not materially changed after contact with hydrogen peroxide or sodium hydroxide solutions. The spectral features of the organic as well as inorganic components of the samples were unchanged. Figure 2 shows the spectra of the Natural biomass sample as an example. Both treatments lead, however, to changes in the intensity ratio of the bands due to $\mathrm{OH}$ groups at about 3180 and $3411 \mathrm{~cm}^{-1}$. The latter band (assigned to hydrogen-bonded surface $\mathrm{OH}$ groups) is of higher intensity after treatment with hydrogen peroxide but the opposite behaviour is observed after treatment with sodium hydroxide. Most probably, the observed change is due to partial ion exchange of $\mathrm{H}^{+}$with $\mathrm{Na}^{+}$.

No significant changes were observed in the spectra collected in the far-infrared region. Small changes in band intensity ratio do not give any reason to suppose changes in the chemical composition and/or structure.

\section{Thermal Treatment at Low Temperatures}

Organics are usually eliminated from inorganic compositions by treatment in oxidizing atmosphere at elevated temperatures. The process is normally accompanied by
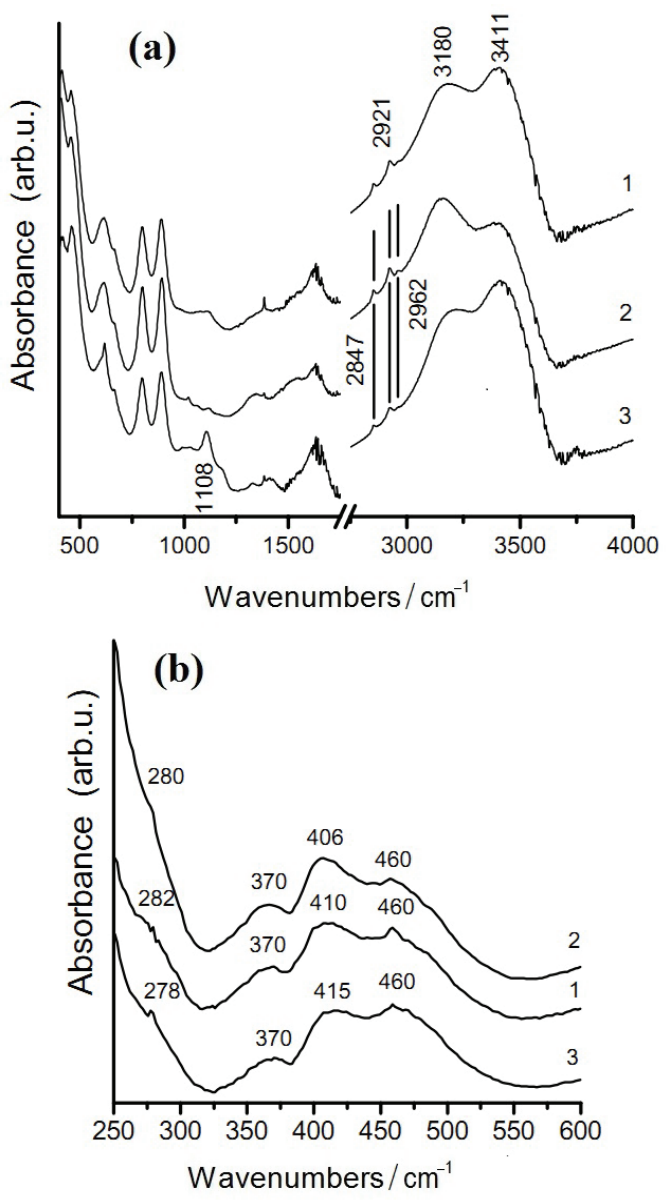

Figure 2. Mid- (a) and far-IR spectra (b) of the Natural biomass sample treated with $30 \% \mathrm{H}_{2} \mathrm{O}_{2}$ or $31 \% \mathrm{NaOH}$ solutions. 1 - Natural biomass, 2 - Natural biomass treated with $\mathrm{NaOH}$, 3 - Natural biomass treated with $\mathrm{H}_{2} \mathrm{O}_{2}$. 


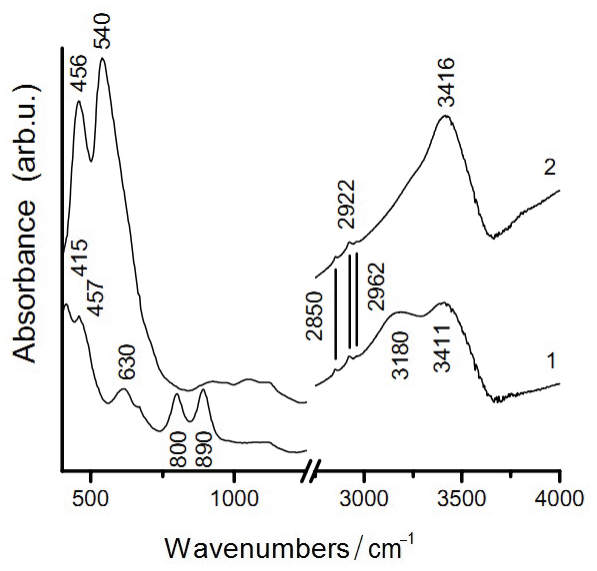

Figure 3. Mid-IR spectra of the Natural biomass sample before (1) and after treatment in oxidative gas mixture up to $250{ }^{\circ} \mathrm{C}(2)$.

changes in the composition and structure of the original material. We attempted to clean up the studied samples by low temperature combustion of organic contamination in oxidative gas flow. The samples were heated at a temperature ramp rate of $10 \mathrm{deg} \mathrm{min}^{-1}$ up to $250{ }^{\circ} \mathrm{C}$ and kept at this temperature for 30 minutes. A flow mixture

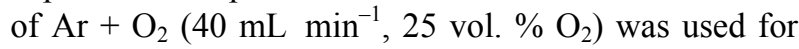
this purpose.

Infrared transmission spectra of a Natural biomass and an Adler-cultivated samples in $\mathrm{KBr}$ pellets were collected after oxidative treatment. Spectra of the Natural biomass sample are displayed in Figures 3 and 4. A strong decrease in intensity of all the bands characteristic of $\alpha$-FeOOH (at about 3180, 890, 800, and $630 \mathrm{~cm}^{-1}$ ) is observed in the spectrum after heating in the gas flow (Figure 3), which gives evidence of dehydration process. Besides, the far-infrared spectrum shows that the treatment at temperatures up to $250{ }^{\circ} \mathrm{C}$ has resulted in bands registered at about 326,457 , and $538 \mathrm{~cm}^{-1}$ (Figure 4), which are characteristic of metal-oxygen vibrations in $\mathrm{Fe}_{2} \mathrm{O}_{3}{ }^{43}$ Thus, the thermally induced spectral changes indicate a phase $\alpha-\mathrm{FeOOH} \cdot x \mathrm{H}_{2} \mathrm{O} \rightarrow \mathrm{Fe}_{2} \mathrm{O}_{3}$ transformation. It is worth to note that the bands at 2850, 2922, and $2962 \mathrm{~cm}^{-1}$ were not changed after dehydration. The weak and poorly resolved bands in the region $900-1250 \mathrm{~cm}^{-1}$ revealed after treatment have already been assigned to $\mathrm{C}-\mathrm{O}, \mathrm{C}-\mathrm{O}-\mathrm{C}$ and $\mathrm{C}-\mathrm{O}-\mathrm{P}$ vibrations in oligo- and polysaccharides that build up a

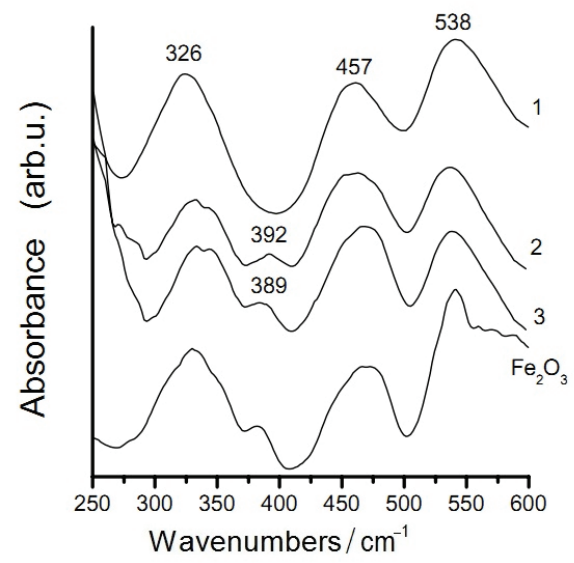

Figure 4. Far-IR spectra of the studied samples after various thermal pretreatments. 1 - Natural biomass after treatment in oxidative gas mixture up to $250{ }^{\circ} \mathrm{C} ; 2$ - Natural biomass after treatment in air up to $860{ }^{\circ} \mathrm{C} ; 3$ - Adler-K after treatment in air up to $1000^{\circ} \mathrm{C}$.

bacterial capsule. ${ }^{47}$ Consequently, the obtained results prove that the presence of organic matter in the studied sample could not be eliminated following the soft oxidizing procedure.

A Mössbauer spectrum of the natural biomass sample, recorded after soft oxidative treatment up to $250{ }^{\circ} \mathrm{C}$, shows the presence of three sextet-type components and one small doublet. Only $\mathrm{Fe}^{3+}$ ions in octahedral coordination are identified. The three sextets have parameters (Table 2) characteristic of highly dispersed $\alpha-\mathrm{Fe}_{2} \mathrm{O}_{3}$ (hematite) with values of the hyperfine field $\left(H_{\text {eff }}\right)$ lower than that of bulk well-crystallized hematite. During the computational process, a three-sextet model was used because the spectral lines manifested nonLorentz character. The present results are the same as those obtained after catalytic measurements of the sample in our previous study. ${ }^{20}$

Information about organic carbon inclusion in the structure of bacterially formed mineral sheaths can be found in the literature. ${ }^{24-29}$ The Natural biomass sample was examined by scanning electron microscopy. SEM images showed particles in the form of needles and spheres with rough surface (Figure 5). In addition, some hollow particles (broken spheres) are registered. The SEM observations give ground to suggest that organic matter is included in the particle structure. Perhaps

Table 2. Calculated values of Mössbauer parameters of the Natural biomass sample after treatment in oxidative gas mixture up to $250^{\circ} \mathrm{C}$

\begin{tabular}{lccccc}
\hline Component & $\mathrm{IS} / \mathrm{mm} \cdot \mathrm{s}^{-1}$ & $\mathrm{QS} / \mathrm{mm} \cdot \mathrm{s}^{-1}$ & $H_{\mathrm{eff}} / \mathrm{T}$ & $\mathrm{FWHM} / \mathrm{mm} \cdot \mathrm{s}^{-1}$ & $G / \%$ \\
\hline $\mathrm{Sxt} 1-\alpha-\mathrm{Fe}_{2} \mathrm{O}_{3}$ & 0.37 & -0.10 & 49.0 & 0.39 & 20 \\
$\mathrm{Sxt} 2-\alpha-\mathrm{Fe}_{2} \mathrm{O}_{3}$ & 0.37 & -0.10 & 47.2 & 0.46 & 37 \\
$\mathrm{Sxt} 3-\alpha-\mathrm{Fe}_{2} \mathrm{O}_{3}$ & 0.37 & -0.09 & 44.5 & 1.08 & 40 \\
$\mathrm{Dbl}-\alpha-\mathrm{Fe}_{2} \mathrm{O}_{3}$ & 0.35 & 0.85 & - & 0.69 & 3 \\
\hline
\end{tabular}



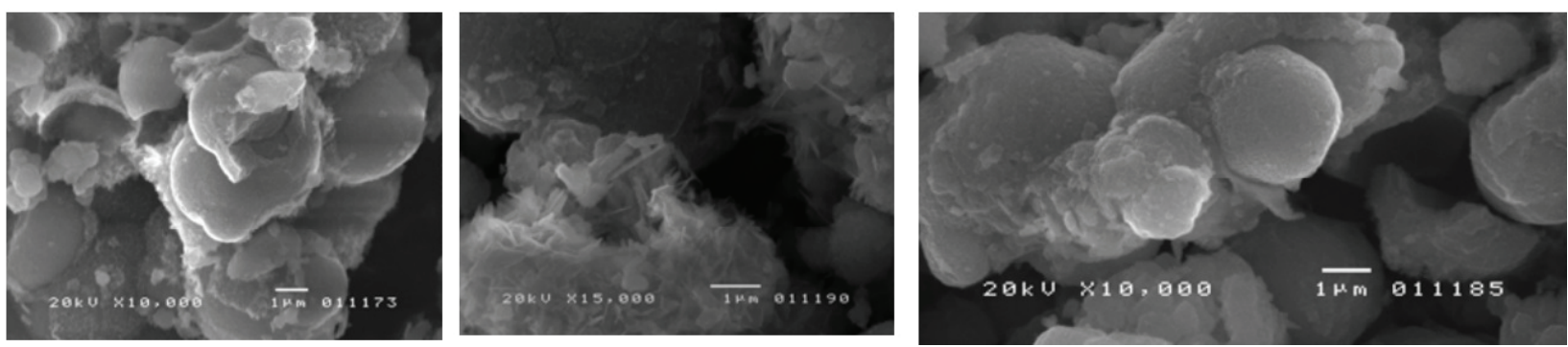

Figure 5. SEM images of a non-treated Natural biomass sample.

some particles contain capsulated organics. Thus, organic rests could hardly be affected by chemical solutions and oxidation under soft thermal conditions could not be effective, either.

\section{Thermal Treatment at Higher Temperatures}

Additional experiments aimed at looking into the phase transformation processes were carried out using simultaneous thermal analysis (TG-dTG/dTA). Analysis of the samples was performed using an oxidative medium (air). Thus, one could gain information about the properties of new materials obtained during high temperature oxidation of natural and laboratory-cultivated biomass and select appropriate conditions for thermal treatment.

TG-dTA/dTG analyses during the thermal treatment of the Natural biomass sample under oxidative conditions demonstrated three stages of transformation characterized by respective thermal effects (Figure 6, Table 3). During the first stage, a mass decrease of $\sim 3.7 \%$ was accompanied by endothermic effects at $\sim 50$ and $\sim 120{ }^{\circ} \mathrm{C}$. These effects can be assigned to dehydration, $\alpha-\mathrm{FeOOH} \cdot x \mathrm{H}_{2} \mathrm{O} \rightarrow \alpha$-FeOOH, namely, removal of weakly bonded (physically adsorbed and crystal hydrate) water. ${ }^{42,48}$ The second stage was characterized by higher mass losses of $\sim 8 \%$ and a strong exothermic effect in the range of $150-300{ }^{\circ} \mathrm{C}$, which covers (compensates) two endoeffects poorly resolved

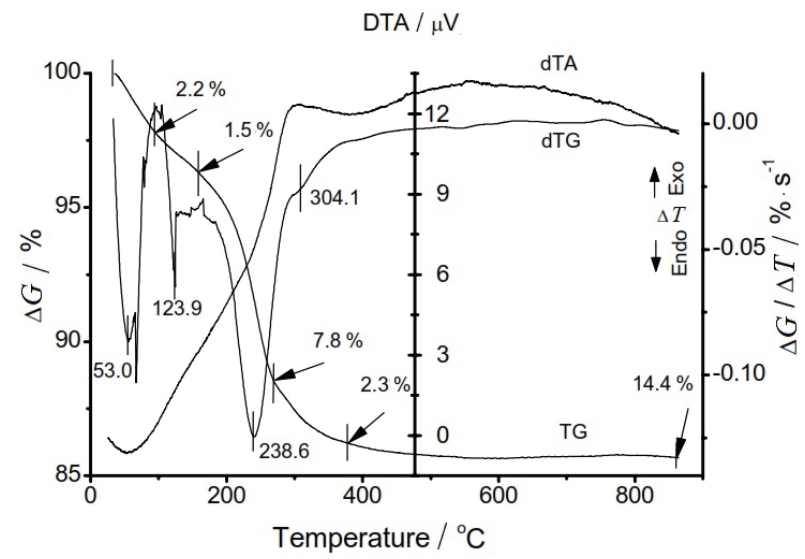

Figure 6. TG, dTA, and dTG curves obtained on thermal treatment of the Natural biomass sample. at $\sim 180$ and $300-380{ }^{\circ} \mathrm{C}$. According to the stoichiometry of the $\alpha$-FeOOH $\left(M=88.8 \mathrm{~g} \mathrm{~mol}^{-1}\right) \rightarrow \alpha-\mathrm{Fe}_{2} \mathrm{O}_{3}(M=$ $\left.159.7 \mathrm{~g} \mathrm{~mol}^{-1}\right)$ transition, mass losses should be about $10.13 \%$. The thermal analysis showed that the resultant transformation of $\alpha-\mathrm{FeOOH}$ to $\alpha-\mathrm{Fe}_{2} \mathrm{O}_{3}$ in the sample takes place in the range of $180-380{ }^{\circ} \mathrm{C}(\Delta G=10.1 \%)$ in accordance with data indicating that both the removal of structural water and the $\alpha-\mathrm{FeOOH} \rightarrow \alpha-\mathrm{Fe}_{2} \mathrm{O}_{3}$ chemical transformation occur mainly in the range of $180-250{ }^{\circ} \mathrm{C}^{20,42,48}$ Also, parallel to iron oxyhydroxide dehydration, the combustion of organic matter in the sample begins within the second interval. Oxidation of organic materials is usually realized between 200 and $600{ }^{\circ} \mathrm{C}$. ${ }^{49}$ Evidence about that is the shoulder of the dTA-peak at $\sim 300{ }^{\circ} \mathrm{C}$ due to the exothermic reaction. In the third temperature range of $380-450{ }^{\circ} \mathrm{C}$, combustion of some residues of organic components (exothermic reaction) is also possible. An important feature of the monitored process is its very small thermal effect associated with crystallization of hematite, $\alpha-\mathrm{Fe}_{2} \mathrm{O}_{3}$, some sintering $\left(\sim 400{ }^{\circ} \mathrm{C}\right)$, and some firm particle packing (about and over $600{ }^{\circ} \mathrm{C}$ ). ${ }^{48}$ It is worth noting that there is an insignificant mass loss (about $0.5 \%$ ) due to the total combustion of organics in the Natural biomass sample.

The results obtained by TG-dTA/dTG explain well the impossibility discussed above to oxidize the organic compounds in the biomass samples at temperatures up to $250{ }^{\circ} \mathrm{C}$. Thus, suitable conditions, different from previously described attempts for destruction/oxidation of organics in biomass, should be applied.

As it was shown in our previous study, Ref. 20, and as discussed above, the biomass (Adler-K sample), cultivated under laboratory conditions, contains $\gamma$-FeOOH, $\mathrm{Fe}_{3} \mathrm{O}_{4}$, and a higher quantity of organics than the natural biomass sample. Therefore, it was reasonable to study the transformations following high temperature treatment. TG-dTA/dTG analysis showed the presence of principally the same three stages in the process of transformation as it was in the case with the Natural biomass sample. The Adler-K sample revealed a small mass loss (about $2.8 \%$ ) up to a temperature of $120{ }^{\circ} \mathrm{C}$ during the first stage (Figure 7, Table 3). It was almost the same as observed with the Natural biomass sample under these conditions and, 
Table 3. TG-dTG data on temperature ranges and mass losses of the Natural biomass and Adler-K samples

\begin{tabular}{|c|c|c|c|c|c|c|c|}
\hline \multicolumn{4}{|c|}{ Natural biomass } & \multicolumn{4}{|c|}{ Adler-K } \\
\hline \multicolumn{3}{|c|}{ Temperature range } & \multirow{2}{*}{ Mass loss / \% } & \multicolumn{3}{|c|}{ Temperature range } & \multirow{2}{*}{ Mass loss / \% } \\
\hline 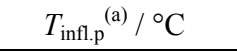 & $T_{\text {start }} /{ }^{\circ} \mathrm{C}$ & $T_{\text {end }} /{ }^{\circ} \mathrm{C}$ & & $T_{\text {infl.p }}^{\text {(a) }} /{ }^{\circ} \mathrm{C}$ & $T_{\text {start }} /{ }^{\circ} \mathrm{C}$ & $T_{\text {end }} /{ }^{\circ} \mathrm{C}$ & \\
\hline 53.0 endo & 31.4 & 93.5 & 2.2 & 40.4 endo & 27.6 & 106.6 & 2.8 \\
\hline 123.9 endo & 93.5 & 157.4 & 1.5 & - & - & - & - \\
\hline 238.6 endo + exo & 157.4 & 268.7 & 7.8 & 273.0 endo & 179.4 & 292.5 & 11.1 \\
\hline 304.1 exo & 268.7 & 377.4 & 2.3 & 310.5 exo & 292.5 & 337.3 & 6.0 \\
\hline- & - & - & - & 346.8 exo & 337.3 & 408.8 & 3.0 \\
\hline \multirow[t]{2}{*}{-} & - & - & - & 463.3 exo & 408.8 & 529.8 & 2.2 \\
\hline & \multicolumn{2}{|c|}{ Total mass loss } & 14.4 & \multicolumn{3}{|c|}{ Total mass loss } & 29.7 \\
\hline
\end{tabular}

(a) Temperature at the inflection point.

obviously, dehydra-tion of weakly bonded water species and crystal hydrate water was also realized. ${ }^{48}$ Moreover, the dTA curve has similar complex character in the range of $150-450{ }^{\circ} \mathrm{C}$. The endothermal effect during the second stage (up to $\sim 310^{\circ} \mathrm{C}$ ) followed at the beginning the same tendency (compare Figures 6 and 7) but a well-defined exoeffect was observed at $280-420^{\circ} \mathrm{C}$. The mass decrease $(\sim 20 \%)$ in this range is higher compared to that with the Natural biomass sample. Similarly, the course of the dTA curve of Adler-K indicates that reactions with opposite thermal effects run together and the exothermic effects have a predominant role. Probably, this part of the dTA curve is consistent with a $\gamma-\mathrm{FeOOH} \rightarrow \gamma-\mathrm{Fe}_{2} \mathrm{O}_{3}$ transformation (endothermic) at 180-300 ${ }^{\circ} \mathrm{C},{ }^{44,48}$ exothermic reactions of magnetite oxidation, $\mathrm{Fe}_{3} \mathrm{O}_{4} \rightarrow \gamma-\mathrm{Fe}_{2} \mathrm{O}_{3},{ }^{42,50,51}$ and (complete) oxidation of organic rests. Taking into account that the amount of magnetite in the studied sample is small ${ }^{20}$ and that its oxidation is culminated at about $375-400{ }^{\circ} \mathrm{C}$, ${ }^{51}$ one may conclude that the effect of magnetite on the course of the dTA curve cannot be significant. $\Delta G$ is about $20 \%$ at $280-420{ }^{\circ} \mathrm{C}$. Theoretical and

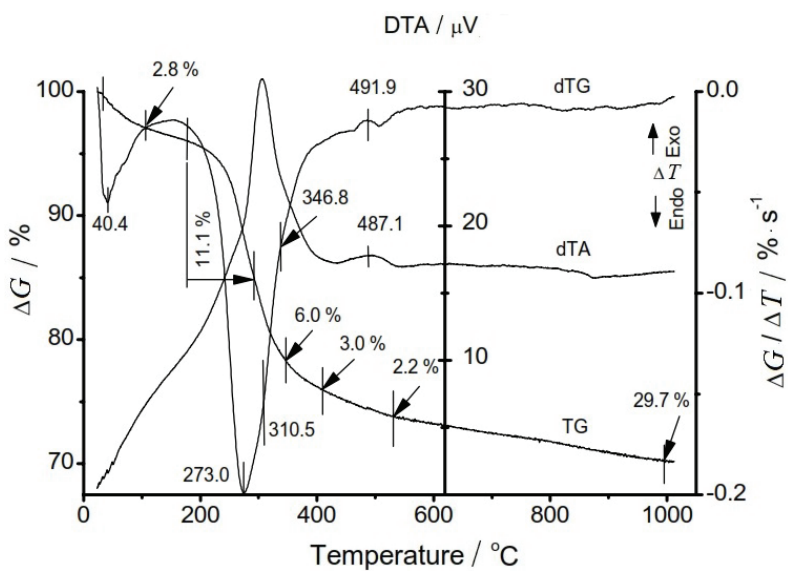

Figure 7. TG, dTA, and dTG curves obtained on thermal treatment of the Adler-K sample. experimental values of the mass loss due to the $\gamma$-FeOOH $(M=88.8) \rightarrow \gamma-\mathrm{Fe}_{2} \mathrm{O}_{3}(M=159.7)$ transition are almost the same -10.13 and $11.1 \%$, respectively. It should be mentioned that theoretically the $\mathrm{Fe}_{3} \mathrm{O}_{4}(M=$ $231.5) \rightarrow \gamma-\mathrm{Fe}_{2} \mathrm{O}_{3}(M=159.7)$ transition results in a mass increase of about $3.4 \%$. This value is small and the general decrease in sample mass covers it. By analyzing the TG curve, it is seen that the mass decrease continues at temperatures above $410{ }^{\circ} \mathrm{C}$. Comparative analysis of the TG curves of the both studied samples showed that over $410{ }^{\circ} \mathrm{C}$ the registered mass loss is 0.5 $\%$ with the Natural biomass sample, while it is $\sim 3.5 \%$ with the Adler-K sample. Probably, the special features of the process described above are due to oxidation of organic rests. Because of their higher amount in the Adler-K sample, this process takes place in a wider temperature interval (up to about $600{ }^{\circ} \mathrm{C}$ ) and it is accompanied by a higher mass loss and a higher exothermal effect. Therefore, the TG-dTA/dTG analysis clearly supports the results obtained by IR spectroscopy that cultivated biomass in the Adler-K sample contains a higher amount of organics. A very small exoeffect is registered at $500{ }^{\circ} \mathrm{C}$ with this sample due to the transformation $\gamma-\mathrm{Fe}_{2} \mathrm{O}_{3} \rightarrow \alpha-\mathrm{Fe}_{2} \mathrm{O}_{3}$ and following crystallization. ${ }^{48,50,51}$ Additionally, a very small thermal effect (up to and about $875^{\circ} \mathrm{C}$ ) is registered in the high temperature range by the end of measurement due to formation of dense $\alpha-\mathrm{Fe}_{2} \mathrm{O}_{3}$ particles and their aggregation. $^{48}$

The Natural biomass and Adler-K samples were studied by Mössbauer spectroscopy after thermal treatment at high temperatures in order to determine the oxidation state of the iron-containing ingredients. The spectrum of the Natural biomass sample has two components - sextets. One sextet component is present in the experimentally obtained spectrum of the Adler-K sample. The Mössbauer parameters are displayed in Table 4. Computer calculations determined the parameters of hyperfine interaction and showed that 
Table 4. Calculated values of Mössbauer parameters of the Natural biomass and Adler-K samples thermally treated up to 860 and $1000{ }^{\circ} \mathrm{C}$, respectively

\begin{tabular}{|c|c|c|c|c|c|}
\hline Sample / Component & IS $/ \mathrm{mm} \cdot \mathrm{s}^{-1}$ & $\mathrm{QS} / \mathrm{mm} \cdot \mathrm{s}^{-1}$ & $H_{\text {eff }} / \mathrm{T}$ & $\mathrm{FWHM} / \mathrm{mm} \cdot \mathrm{s}^{-1}$ & $G / \%$ \\
\hline \multicolumn{6}{|l|}{ Natural biomass } \\
\hline Sxt1 $-\alpha-\mathrm{Fe}_{2} \mathrm{O}_{3}$ & 0.37 & -0.11 & 51.4 & 0.34 & 88 \\
\hline $\mathrm{Sxt} 2-\alpha-\mathrm{Fe}_{2} \mathrm{O}_{3}$ & 0.36 & -0.11 & 50.4 & 0.35 & 12 \\
\hline \multicolumn{6}{|l|}{ Adler-K } \\
\hline $\mathrm{Sxt}-\alpha-\mathrm{Fe}_{2} \mathrm{O}_{3}$ & 0.36 & -0.11 & 51.4 & 0.28 & 100 \\
\hline
\end{tabular}

only iron ions in the $3+$ oxidation state with octahedral coordination (isomer shift) are available. They are characteristic of a hematite phase, $\alpha-\mathrm{Fe}_{2} \mathrm{O}_{3}$, present in the treated samples. Hematite is bimodal dispersed in the Natural biomass sample. Despite the high temperature treatment (860 and $1000{ }^{\circ} \mathrm{C}$, respectively), the particles still remain in the nano-size range.

The infrared spectra of both the Natural biomass and Adler-K samples, collected after high temperature treatment in air, manifested the presence of hematite, only (Figure 4). Comparative analysis, however, shows that the spectra of the Natural biomass sample after treatment up to $250{ }^{\circ} \mathrm{C}$ and $860{ }^{\circ} \mathrm{C}$ are different (a band at $392 \mathrm{~cm}^{-1}$ appears) despite a hematite phase formed during the techniques applied to both samples. The spectra of the samples treated at higher temperatures match better with the spectrum of used hematite standard. According to the results obtained from Mössbauer data analysis, particles of various sizes are formed after treatment up to $250{ }^{\circ} \mathrm{C}$, while after treatment up to $860{ }^{\circ} \mathrm{C}$ two groups of particle sizes are present in the Natural biomass sample.

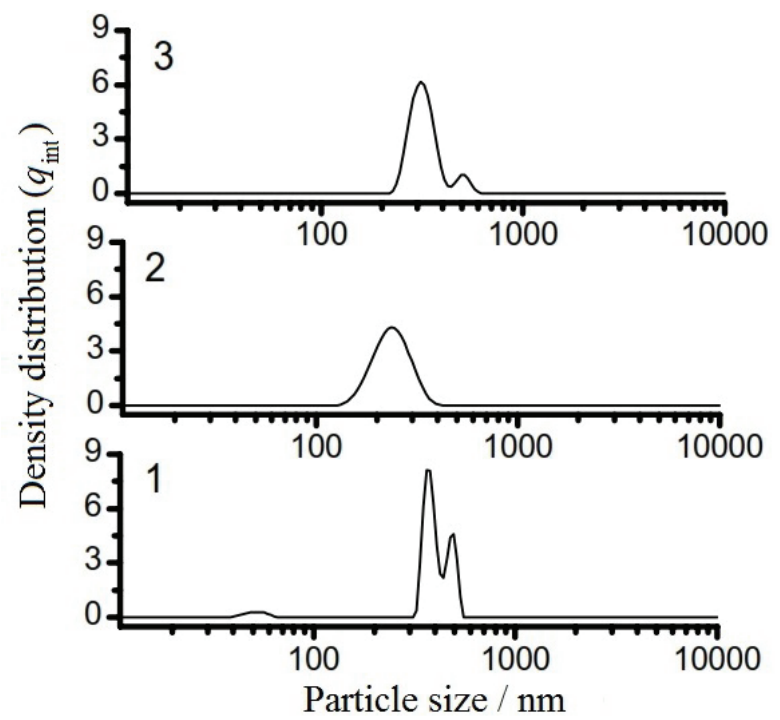

Figure 8. Particle size distribution in thermally treated samples: 1 - a Natural biomass sample treated up to $250{ }^{\circ} \mathrm{C}$, 2 - a Natural biomass sample treated up to $860{ }^{\circ} \mathrm{C}$, 3 - an Adler-K sample treated up to $1000{ }^{\circ} \mathrm{C}$.
Particle sizes in both samples, acquired by PCCS are in line with the supposition made above. Figure 8 shows particle size distributions determined for the three studied samples. The correlation functions obtained are characterized by a different number of peaks corresponding to the hydrodynamic radii of the particles. They can be clearly distinguished in the figure and their values are determined as follows: 53, 362, and $493 \mathrm{~nm}$ (for a Natural biomass sample treated up to $250{ }^{\circ} \mathrm{C}$ ); $236 \mathrm{~nm}$ (for a Natural biomass sample treated from ambient temperature up to $860{ }^{\circ} \mathrm{C}$ ); 310 and $493 \mathrm{~nm}$ (for an Adler-K sample treated up to $1000^{\circ} \mathrm{C}$ ). The results show that the samples are polydisperse to a different extent. Particular polydispersity indices (PdI) were found to be 0.393 (for a Natural biomass sample treated up to $250{ }^{\circ} \mathrm{C}$ ), 0.211 (for a Natural biomass sample treated from ambient temperature up to $860{ }^{\circ} \mathrm{C}$ ), and 0.258 (for the Adler-K sample treated up to $1000{ }^{\circ} \mathrm{C}$ ). The obtained values are due to the presence and transformation of particle agglomerates during sample thermal treatment. Despite all processes of chemical decomposition and phase transformations, the trend of particle size distribution observed with Mössbauer data analysis is retained. In comparison with the samples treated at higher temperatures, a relatively broader particle size distribution is intrinsic with the Natural biomass sample treated up to $250{ }^{\circ} \mathrm{C}$.

A relatively large difference in particle size distribution was found during comparative analysis of the Natural biomass samples treated up to $250{ }^{\circ} \mathrm{C}$ and $860^{\circ} \mathrm{C}$ (Figure 8, curves 1 and 2). A monomodal distribution (around $236 \mathrm{~nm}$ ) after treatment at $860{ }^{\circ} \mathrm{C}$ in air suggests indirectly that the combustion of organic rests has a two-way effect on the particles. The exothermic process results in a local overheating and favours an agglomeration of the small particles but, in the case of larger particles, this process leads to fragmented entities. Comparison between the Natural biomass and Adler-K samples treated at a high temperature (860 and $1000{ }^{\circ} \mathrm{C}$, respectively) shows that particle size scattering is larger in Adler-K with most population around $310 \mathrm{~nm}$ (Figure 8, curves 2 and 3). This difference is due to certain influence of the two exothermic reactions in the case of the Adler-K sample: combustion of a higher amount of organic rests and $\mathrm{Fe}_{3} \mathrm{O}_{4}$ oxidation. 


\section{CONCLUSION}

The specificity in composition of Natural biomass obtained from Sphaerotilus-Leptothrix group of bacteria and that of laboratory-cultivated in Adler's medium (containing $\alpha-\mathrm{FeOOH}$ and $\gamma-\mathrm{FeOOH}$, respectively, as principal components) is preserved after chemical treatment with $\mathrm{H}_{2} \mathrm{O}_{2}$ and $\mathrm{NaOH}$ at room temperature. However, thermal treatment at temperatures between 250 and $600{ }^{\circ} \mathrm{C}$ gives rise to transformation of the initial FeOOH compounds.

Acknowledgements. The authors are thankful to the National Science Fund of Bulgaria (Project DID-02/38/2009) and to the European Social Fund at the European Union (Grant BG051PO001-3.3.06-0050) for financial support. This work was also supported by the Bulgarian Academy of Sciences and the Slovak Academy of Sciences through the bilateral project 'Mechanochemically synthesized nanomaterials, their characterization, photocatalytic and anticancer properties'. Assistance by Dr. M. Fabian, Institute of Geotechnics of the Slovak Academy of Sciences, in PCCS measurements and discussion is greatly acknowledged.

\section{REFERENCES}

1. H. Hashimoto, S. Yokoyama, H. Asaoka, Y. Kusano, Y. Ikeda, M. Seno, J. Takada, T. Fujii, M. Nakanishi, and R. Murakami., J. Magnet. Magnet. Mater. 310 (2007) 2405-2407.

2. T. Sakai, Y. Miyazaki, A. Murakami, N. Sakamoto, T. Ema, H. Hashimoto, M. Furutani, M. Nakanishi, T. Fujiia, and J. Takada, Org. Biomol. Chem. 8 (2010) 336-338.

3. B. Xin, D. Zhang, X. Zhang, Y. Xia, F. Wu, S. Chen, and L. Li, Bioresour. Technol. 100 (2009) 6163-6169.

4. J. A. Rentz, I. P. Turner, and J. L. Ullman, Water Res. 43 (2009) 2029-2035.

5. D. Emerson, E. J. Fleming, and J. M. McBeth, Ann. Rev. Microbiol. 64 (2010) 561-583.

6. U. Schwertmann and R. Cornell, Iron oxides in the laboratory: preparation and characterization Second completely revised and extended edition, Wiley-VCH, Weinheim, New York 2000.

7. R. W. Fitzpatrick, R. Naidu, P. G. Self, in: H. C. W. Skinner and R. W. Fitzpatrick (Eds.), Biomineralization Processes of Iron and Manganese - Modern and Ancient Environments, Catena Supplement 21, Catena Verlag, Reiskirchen, Germany, 1992, p. 263-286.

8. D. A. Ankrah and E. G. Sogaard, $13^{\text {th }}$ Int. Water Technol. Conf., IWTC 13, 2009, Hurghada, Egypt, p. 999-1005.

9. K. B. Narayanan and N. Sakthivel, Adv. Colloid Interface Sci. 156 (2010) 1-13.

10. H. Jung, J.-W. Kim, H. Choi, J.-H. Lee, and H.-G. Hur, Appl. Catal. B: Environ. 83 (2008) 208-213.

11. S. Veleva, Z. Cherkezova-Zheleva, M. Shopska, D. Paneva, V. Grudeva, M. Iliev, L. Slavov, I. Nedkov, G. Kadinov, I. Mitov, M. Mladenov, and D. Kovacheva, Nanoscience and Nanotechnology, Vol. 12 (Eds. E. Balabanova and I. Dragieva), Bulgarian Academy of Sciences and National Coordination Council on NanoTechnology, Sofia, 2012, p. 135-138.

12. S. Jin, H. Deng, D. Long, X. Liu, L. Zhan, X. Liang, W. Qiao, and L. Ling, J. Power Sources 196 (2010) 3887-3893.

13. I. Katsoyannis, A. Zoubolis, H. Althoff, and H. Bartel, Chemo- sphere 47 (2002) 325-332.

14. F. G. Ferris, R. O. Hallberd, B. Lyven, and K. Pedersen, Appl. Geochem. 15 (2000) 1035-1042.

15. I. A. Katsoyiannis and A. I. Zouboulis, Water Res. 38 (2004) 1726.

16. I. Takeda, H. Somura, and Y.Mori, Ecol. Eng. 36 (2010) 1064 1069.

17. J. Rentz, Phosphorus removal potential using biogenic iron oxides, WERF, USA, 2010.

18. H. Jung, H. Park, J. Kim, J.-H. Lee, H. - G. Hur, N. V. Myung, and H. Choi, Environ. Sci. Technol. 41 (2007) 4741-4747.

19. B. Kazprzyk-Hordern, M. Ziolek, and J. Nawrocik, Appl. Catal. B 46 (2003) 639-669.

20. M. Shopska, Z. Cherkezova-Zheleva, D. Paneva, M. Iliev, G. Kadinov, I. Mitov, and V. Groudeva, Cent. Eur. J. Chem. 11 (2013) 215-227.

21. K. Mandai, T. Korenaga, T. Ema, T. Sakai, M. Furutani, H. Hashimoto, and J. Takada, Tetrahedron Lett. 53 (2012) 329-332.

22. T. Ema, Y. Miyazaki, I. Kozuki, T. Sakai, H. Hashimoto, and J. Takada, Green Chem. 13 (2011) 3187-3195.

23. T. Ema, Y. Miyazaki, T. Taniguchi, and J. Takada, Green Chem. 15 (2013) 2485-2492.

24. C. S. Chan, S. C. Fakra, D. S. Edwards, D. Emerson, and J. F. Banfield, Geochim. Cosmochim. Acta 73 (2009) 3807-3818.

25. F. G. Ferris, R. O. Hallberg, B. Lyven, and K. Pedersen, Appl. Geochem. 15 (2000) 1035-1042.

26. K. Benzerara, T. H. Yooh, T. Tyliszczak, B. Constantz, A. M. Spormann, and G. E. Brown, Jr., Geobiology 2 (2004) 249-259.

27. D. Emerson, H. Lin, L. Agulto, and L. Lin, Bioscience 58 (2008) 925-936.

28. T. Suzuki, H. Hashimoto, H. Ishihara, T. Kasai, H. Kunoh, and J. Takada, Appl. Environ. Microbiol. 77 (2011) 7873-7875.

29. M. Furutani, T. Suzuki, H. Ishihara, H. Hashimoto, H. Kunoh, and J. Takada, Minerals 1 (2011) 157-166.

30. K. L. Straub, M. Benz, and B. Schink, FEMS Microbiol. Ecol. 34 (2001) 181-186.

31. D. Emerson, in: D. R. Lovley (Ed.), Environmental microbemetal interactions, ASM Press, Washington, D. C., 2000.

32. D. Emerson, in: J. Reitner and V. Thiel (Eds.), Encyclopedia of geobiology, Springer Netherlands, 2011.

33. D. Emerson and C. Moyer, Appl. Environ. Microbiol. 63 (1997) 4784-4792.

34. D. Emerson, J. Tang, R. J. Cote, and R. L. Gherna, in: C. A. Reddy et al. (Eds.), Methods for general and molecular microbiology, $3^{\text {rd }}$ Edition, ASM Press, 2007.

35. D. Ellis, Microbiology of the iron-depositing bacteria, Wexford College Press, Palm Springs, CA, 2003.

36. S. Winogradsky, Ann. Inst. Pasteur 5 (1891) 92 et 577

37. R. Lieske, Z. Bakt. Parasitenk. Infektionskr. Hyg. Abt. II 49 (1919) 413-425.

38. W. L. van Veen, Antonie van Leeuwenhoek 39 (1973) 189-205.

39. W. W. Leathen, N. A. Kinsel, and S. A. Braley, J. Bacteriol. 72 (1956) 700-704.

40. V. Groudeva, R. Ilieva, R. Angelova, and M. Iliev, Biotechnol. Biotechnol. Equip. (in press)

41. B. Weckler and H.D. Lutz, Eur. J. Solid State Inorg. Chem. 35 (1998) 531-544.

42. U. Schwertmann and R. Cornell, Iron Oxides in the Laboratory, Weinheim, New York-Basel-Cambridge, 1991.

43. A. U. Gehring and A. M. Hofmeister, Clays Clay Miner. 42 (1994) 409-415.

44. S. Music, A. Saric, S. Popovic, K. Nomura, and T. Sawada, Croat. Chem. Acta 73 (2000) 541-567.

45. T. D. Glotch and M. D. Kraft, Phys. Chem. Minerals 35 (2008) 569-581.

46. L. H. Little, Infrared spectra of adsorbed species, Academic press Inc., London, New York, 1966. 
47. C. Rubio, C. Ott, C. Amiel, I. Dupont-Moral, J. Travert, and L. Mariey, J. Microbiol. Methods 64 (2006) 287-296.

48. V. Balek and J. Subrt, Pure Appl. Chem. 67 (1995) 1839-1842.

49. M. E. Brown, Introduction to thermal analysis. Techniques and applications, $2^{\text {nd }}$ Edition, Kluwer Academic Publishers,
Dordrecht, the Netherlands, 2001.

50. R. M. Cornell and U. Schwertmann, The Iron Oxides. Structure, Properties, Reactions, Occurrences and Uses, Second Completely Revised and Extended Edition, Wiley-VCH Verlag GmbH and Co. KGaA, Weinheim, 2003.

51. H. Lepp, Am. Mineralogist 42 (1957) 679-681. 